\title{
Relationship Between General Education and Ideological and Political Education in TCM Colleges' Teaching
}

\author{
Yurong Xuan \\ Henan University of Traditional Chinese Medicine, Zhengzhou Henan, 075000, China
}

Keywords: General education, Ideological and political education, TCM colleges, Promotion, Combination path

\begin{abstract}
In China, modern Chinese medicine colleges attach more emphasis on professional education, so the resulting contrast to Western medicine, understand the problem and makes the introduction of General Education in the West become necessary. On the other hand, in order to keep pace with tight times, based on the value orientation of quality education, comprehensive thinking and improve ideological and political education in the School of Medicine it is also extremely important. Therefore, the introduction and combination of the two education inevitably sparks, lead to more thinking. This article focuses on the education of the student about two TCM Colleges of mutual promotion and elaborated school for both "East meets West" fusion realization.
\end{abstract}

\section{Introduction}

Training professionals of Chinese medicine in an emphasis on traditional culture rooted in the soil, called "As a healer, you shall know astronomy, geography and personnel." So now the TCM colleges pay more attention to personnel training all-rounder and rounder. In contemporary society, many Chinese TCM academies modeled on Western medicine teaching curriculum education system, instead of discarding the traditional and the contemporary theory advocated humanistic thought, which makes professional orientation TCM colleges educating people pattern is becoming increasingly apparent, the traditional mode of education lopsided.

\section{General education and ideological and political education in China's TCM colleges}

TCM colleges and importance of professional education, ideological and political education in traditionally, but general education is the National Education after advocated a comprehensive upgrade of the new educational thinking ideas. Therefore, before the integration of the two educational institutions in TCM education policy, it is necessary to understand the need for the introduction and implementation of two educational problems that exist.

\section{Traditional ideological and political education in TCM colleges}

Significance OF ideological and political education in TCM colleges

Training professionals of Chinese medicine is first humanistic culture, after the first person into health, only pure and noble ethics can become a qualified doctor. As Einstein said, "Education can make useful professional machines to society, but it can not cultivate a harmonious development of man. If you cannot train people of high moral quality and distinctive recognition ability in professional education, and that he together with his expertise on more like a trained dog, and not a complete person. "Chinese medicine professional education institutions can only give students a survival skill, but when the students into the community, the mere possession of medical skills is not enough, he must also have the right way to look at this world and life and richer viability.

Secondly, in a social point of view, the goal of ideological and political education is to train students TCM colleges form a higher political acceptance that culture Students have a good socialist core values, thus shaping their perfect personality. This is the basic requirements of the current Communist Party on College Students' Talents, and also the basic requirements of the times. 
Problems encountered during implementation of ideological and political education in TCM colleges Poor mental capacity of students

Not only TCM colleges, our students prevailing problem of poor mental capacity, almost all college students have varying degrees of mental disorder, which leads them to drop out, drop-out phenomenon occurs even suicide. This is the more serious manifestations of TCM colleges, if TCM majors can not have a good psychological quality, even their own physical and mental health are not properly grasp how he qualified to become a life-saving doctor. Students in TCM Colleges 2015 survey in a province on the show, there are nearly a quarter of the students TCM colleges various potential psychological problems, and some could not even finish school, they are ideological and political education in Traditional Chinese Medical Universities to carry out the formation of an invisible psychological barrier.

Excess self-awareness

Although today is the emphasis on the era of personalization, but if self-conscious college students surplus, too much emphasis on highlighting self-personality, self-concept is too strong, it will lead to excessive expansion of personality, even making humanity distorted. Cultivated TCM colleges are life-saving altruistic, it requires students to others, to the collective, the community has a responsibility, not arrogant, lack of accountability egoist. This also explains the ideological and political education in colleges and universities now in TCM personnel training of a single weak.

Weak humanities consciousness

Today, whether it is social or school, are overly influenced by utilitarianism, the emphasis on practical teaching TCM colleges, light thinking, heavy eyes, light-term phenomenon is particularly serious. And students generally believe that political education is too boring, for their own professional development and the future does not make much sense. Professional school academic curriculum coupled with the scheduled task very closely heavy, specialized learning occupied most of the time, so the ideological and political education almost unnoticed, resulting in students' humanistic qualities and awareness is very limited.

To sum up, Chinese colleges and universities carry out ideological and political education, since too theoretical and unity of their education, so most students are unable or unwilling to accept the initiative, which revealed a heavy ideological and political education theory, light practice drawbacks. Therefore, in today's era of ideological education so open, the introduction of Western general education, culture and improve ideological personality of college students, focus on comprehensive education for their theory and practice are two advantages of education is to have some significance and necessity .

\section{Necessity of general education in TCM colleges}

General Education originated in the West in ancient Greece, it is a typical liberal people education, so it is also known as Liberal Education. In the late 19th century, the European Free school with a liberal arts education based on evolved later transformed into general education in the United States advocated. The emphasis is on general education and the formation of the humanistic value enhancement of human mental activity of a rich personality, that want to train "complete man", so it emphasizes the ability of college students of four kinds of culture in the modern universities: the effective ability to think, clear judgment, clear thinking, communication skills and cognitive ability to identify universal values. In short, is to train people loyal to the motherland thanks to the community, the family is responsible for the behavior of their parents honor ideology. On the professional side to achieve mental health, knowledge and skills need superb, good communication and expression, and others more. In life, we must learn to pay attention to the basic necessities of health and behaviors of courtesy, to learn to have a quality of life. The final step is to learn whether it is life or work must have the courage of your convictions and the ability to think rationally, it is possible to resist the temptations of the outside world to bring their own, to have a man of principles and the bottom line. Overall, general education is to cultivate a socially responsible citizen of justice, it does not involve professional and utilitarian, but it can affect college students learning professional skills attitudes and behavior, so that in college carry out general education system is diverse and lengthy process. The 
introduction of Western institutions of general education of Chinese medicine, and indeed hope it can help traditional ideological and political education for the training of TCM personnel have a wealth of knowledge, unique vision and benevolence Rende and lay the base lay. Allow the Chinese students not only have the mentality of contemporary social interaction with others and the ability to adapt to the comprehensive development of the times, but also in line with the traditional Chinese education advocated by the classical lean our content, do contemporary excellent all-round development of TCM personnel [1].

\section{Mutual promotion between general education and ideological and political education in TCM colleges}

General education attaches emphasis on traditional education reform, its ability to combine the advantages of the free elective professional majors between targeted General Education. The ideological and political education system of general education institutions to introduce Chinese medicine has diversified role.

\section{Enhance implicit education role of ideological and political education}

In the West, general education can play a role in ideological and political education, because Western countries have not called the "ideological and political education" courses, general education and therefore strengthen ideological and political education to undertake this course of action implicit education portal . Our TCM colleges is great emphasis on traditional culture and academic atmosphere of the occasion education, advocacy and skepticism spirit of freedom, and therefore the study of medicine were not only direct single theory course teaching, but rather the need for the concept of culture through general education just through educational courses on the theory of non-traditional ideological and political education to make up for the unity of the students' education. Through practical activities or incentives to guide and shape the students correct ideological and political consciousness, and the formation of student conduct certain norms and constraints.

\section{Play role of consciousness of innovation}

TCM colleges respect the concept of traditional Chinese medicine, but also to innovation, so the contemporary Chinese medicine attaches great importance to personnel training innovative ability. Ideological education emphasizes innovation theory foundation, and general education is an important means to improve students' innovative ability strengthened. For college students, innovation is not limited IQ level of the individual, but also his way of thinking to accept the theory of knowledge, independent personality and creative motives, that is, people's emotional intelligence. It is not enough to strengthen general education ideological and political education in China's traditional culture of EQ personality, instead of the traditional higher education imitate others, there is no sense of innovation drawbacks, from the theoretical and practical aspects of talent to strengthen all-round training, so that students has perfect EQ and IQ, the courage to explore and create, will be China's next higher level into a new phase [2].

\section{Integration development approach of general education and ideological and political education in TCM colleges}

\section{Scientifically build TCM colleges education system}

TCM colleges and universities need to build public recognition of the educational system, in close connection with the ideological and political relationship between higher education and general education, thereby establishing a comprehensive course management system, so that students can continue to go in the right frame of mind philosophy and educational approach road form system. Meanwhile, TCM colleges should combine political education content to enrich the general education model to improve the evaluation mechanism in schools. Through evaluation mechanism, students can 
more quickly and clearly recognize their own lives in learning deficiencies, and be corrected in a short time, to get progress.

Rich educational system and educational institutions in TCM terms, I believe that it is necessary to integrate resources of university, and even medical institutions can be grouped into a comprehensive university system, become a part of a comprehensive university, which the medical colleges through Education and knowledge have helped to carry out ideological and political education. According to a US survey showed that US domestic composite score highest in the world-class Higher School of Medicine are located in the university system, for example, Harvard Medical School, the University of California, San Francisco School of Medicine, and so on. The reason why medical school in order to develop more comprehensive university system, its essential reason is that the university system to make up for the lack of independent medical school and school system in terms of education level, it is a comprehensive university system, for example, integration of the School of Medicine natural sciences and social sciences, its superior running conditions satisfy the experimental conditions and the humanities faculty of Medicine, but it also provides students with a high-quality, content-rich professional basic courses and humanities ideological and political course, so that regardless of Medicine is constructed in the education system or economic support are no worries. Therefore, the protection of supports comprehensive university system, the medical school of discipline truly on the cross and penetration between general education and ideological and political education for medical students increase of knowledge, but also improve their humanistic qualities.

\section{Update education skills}

General education emphasizes interdisciplinary education and educational content richness, General Education in Traditional Chinese Medical Universities in the hope that take advantage of this rich teaching point of view and way of ideological and political education in colleges and universities. In other words, the university is not a single theory to traditional teaching methods to instill in students ideological and political education content, as proven, purely ideological and political education to teach will bring the opposite effect, so that students initiation resentment, would not achieve the ideological and political ideal for the purpose of education. Therefore, China should learn from TCM colleges teaching methods of ideological and political education abroad, carried out by means of general education content spread of ideological and political education. For example, in teaching methods, flexible and take professional content lectures, panel discussions, PBL teaching method, etc., or be the subject of a medical simulation scenarios for students to open training base, teaching activities provide opportunities for them to practice the combination of theory through Practice Education to solve the problem. In practice the process of education in ideology and political education to infiltrate the idea of general education to students, let them exercise acted in learning, cooperation and mutual assistance capability.

In terms of the assessment should be appropriate to reduce the proportion of theoretical teaching content, student assessment appropriate to increase the immediate response, random contents understanding and ability to inspire them to create more professional and independent opinion proposition. In addition, we must vigorously during the exam written examinations oral combination, such as adding a packet in oral discussion, debate speech contest and so on. Usually while increasing the weight ratio of classroom assessment content, allowing students to focus on learning the usual course knowledge, develop their beginnings and ends, such as a serious attitude. Teach them how to learn, to multi-level, multi-angle, multi-form of general education strategy to penetrate the ideological and political education, not deliberately allow students to learn specific ideological and political course.

\section{Open up second classroom}

Finally, TCM colleges purpose to clear itself of academic training, it is not only in the promotion of social science and technology advance, more importantly, it is to enhance the cultural quality of the whole citizens. Therefore TCM colleges should open the second class, invite famous professors to teach medical courses, seminars instructors hope to pass from a medical point of life theory, ideological and political theory, the ideological and political education professional point of view to 
infiltrate the minds of students, which not only general education can ease the conflict, ideological and political education and professional education among, also more in line with the characteristics of college students thinking [3].

\section{Conclusions}

College of Traditional Chinese Medicine is the essence of traditional Chinese culture to carry forward and cultivate talents important life-saving Medical education area, so the spread of ideological and political education is a major responsibility and self-evident. On this basis, the introduction of general education, it is hoped that the concept of specialized education and beyond utilitarian, practical, humanistic philosophy can flexibly and effectively into the ideological and political education, and tap the inherent potential of the individual student body and spirit temperament.

\section{References}

[1] Zheng Yuling. Thoughts on TCM colleges implementing general education. TCM Study,2015,28(11):1-3.

[2] Gao Qingyun. College ideological and political education study under general education reference domain. North University of China, 2014.16-25.

[3] Yang Dongliang. General education of American Medical colleges and enlightenment. Hebei Normal University,2014.29-32. 